\title{
Decreased plasma fibronectin concentrations in preterm infants with septicaemia
}

Department of Newborn Services, King Edward Memorial Hospital for Women, Perth, Western Australia M P Dyke

Department of Paediatrics and Child Health, Flinders Medical Centre, Adelaide, South Australia

K D Forsyth

Correspondence to: Professor Kevin Forsyth, Department of Paediatrics and Child Health, Flinders Medical Centre, Bedford Park 5042, Adelaide, South Australia, Australia.

Accepted 7 December 1992

\author{
Mark P Dyke, Kevin D Forsyth
}

\begin{abstract}
Changes in plasma fibronectin concentrations were determined during bacterial septicaemia in extremely preterm infants. The study was a prospective study of fibronectin concentrations in infants of less than 30 weeks' gestation. Concentrations were determined at birth, before sepsis, and throughout the episode of sepsis.
\end{abstract}

Fibronectin concentrations at birth or immediately before sepsis were not significantly different between those infants who developed septicaemia and those who did not $(98$ (15) $v 97$ (10) $\mu \mathrm{g} / \mathrm{ml})$. In the infants with septicaemia, fibronectin concentrations decreased significantly on day 1 (106 (13) $v 173$ (18) $\mu \mathrm{g} / \mathrm{ml}$ for the controls) and remained significantly lower on day 2 (123 (26) $v 201$ (17) $\mu \mathrm{g} / \mathrm{ml})$. By day 5 fibronectin concentrations had increased and were no longer statistically different from controls.

Fibronectin is a key modulator of the immune response, with important functions in neutrophil adhesion, bacterial opsonisation, $T$ cell activation, and vascular integrity. Acute depletion of plasma fibronectin during sepsis in preterm neonates may further abrogate their ability to control sepsis.

(Arch Dis Child 1993; 68: 557-560)

Although considerable progress has been made in improving the survival of very low birthweight infants, the morbidity and mortality due to neonatal sepsis remain disturbingly high. ${ }^{1}$ The pathogenesis of such infections is multifactorial and includes the breaching of skin and mucosal barriers, ${ }^{2}$ exposure to nosocomial pathogens, ${ }^{3}$ multiple courses of antibiotics, and immaturity of the host defence mechanisms. ${ }^{4}$ In this context attention has focused on fibronectin in an attempt to define its role in the acute septic state.

Fibronectin is a high molecular weight glycoprotein which is found in two distinct forms: an insoluble form found within the extracellular matrix of cells and a soluble form in plasma and interstitial fluid. ${ }^{56}$ The full range of functions of fibronectin is not completely understood, but cell associated and soluble forms are thought to play a key part in the maintenance of vascular integrity. In addition, plasma fibronectin affects wound healing, blood coagulation, and immunological clearance of injured tissue and antibody coated micro-organisms. ${ }^{7}$ Fibronectin also displays a number of important features in relation to host defence against infection, including mediation of macrophage particulate endocytosis $^{8}$ and polymorphonuclear leucocyte phagocytosis of erythrocytes and bacteria. ${ }^{9}$ Fibronectin acts as a potent chemoattractant for monocytes ${ }^{10}$ and for neutrophils in the presence of hyaluronic acid. ${ }^{11}$ It enhances the secretion of interleukin-1 ${ }^{12}$ and possesses strong binding sites for many potential neonatal pathogens including staphylococcus ${ }^{13}$ and streptococcus. ${ }^{14}$ Fibronectin enhances the interaction between phagocytes and antibody opsonised bacteria ${ }^{15}$ and increases bactericidal activity in macrophages.

Concentrations of fibronectin have been shown to be lower in term newborn infants than in older children and adults ${ }^{16}$ and it has been suggested that in preterm infants concentrations may be lower still. ${ }^{17}$ In adult patients fibronectin concentrations have been shown to decrease during acute severe illness, including burns and sepsis. ${ }^{18}$

In this study a group of extremely preterm infants, 24-29 weeks' gestation, was studied during episodes of bacterial septicaemia to determine the changes in fibronectin concentrations.

\section{Subjects and methods}

Informed consent was obtained from parents in accordance with the guidelines of the ethics committee of the King Edward Memorial Hospital. All infants of less than 30 weeks' gestation live born at this hospital were eligible for enrolment, with the exception of those with major congenital malformations or congenital infections. Samples of umbilical cord blood (day 0 ) and serial samples of blood drawn from arterial lines, venepuncture, or by heel prick were obtained for each infant on days $1,2,3,7$, $10,14,28$, and 56 of life to establish baseline values. In addition, where symptoms suggestive of infection prompted a septic workup, further samples were drawn at the time of those investigations (day 1), on the following day (day 2), and after five days and seven to 10 days. Samples were drawn into EDTA, transported to the laboratory within 12 hours of collection, and the plasma stored at $-70^{\circ} \mathrm{C}$ until assayed. On the basis of bacterial cultures, supportive laboratory evidence in the form of white blood cell count and $\mathrm{C}$ reactive protein concentration, and clinical response to treatment, the infants were subsequently divided into septic (study) and non-septic (control) groups.

LABORATORY METHODS

Plasma fibronectin concentrations were measured by an enzyme linked immunosorbent 
assay (ELISA) developed in our laboratory. Polystyrene plates were coated with a rabbit antihuman fibronectin antibody (Dako) by placing $100 \mu \mathrm{l}$ of a 1:1000 dilution of the antibody in carbonate coating buffer in each well and leaving the plates overnight at $4^{\circ} \mathrm{C}$. The plates were washed four times with a mixture of phosphate buffered saline (PBS) and Tween 20 between each step of the ELISA. Nonspecific binding was prevented by blocking the plates with $100 \mu \mathrm{l}$ of a $1 \%$ bovine serum albumin solution in PBS incubated for 30 minutes at $37^{\circ} \mathrm{C}$. A $100 \mu \mathrm{l}$ volume of a 1:1000 dilution of patient plasma in PBS was then added to each well and incubated at $37^{\circ} \mathrm{C}$ for one hour. A 1:150 dilution of mouse antihuman fibronectin antibody (FN4) was then added to each well and incubated at $37^{\circ} \mathrm{C}$ for a further hour. A $100 \mu$ l volume of a 1:1000 dilution of peroxidase conjugated goat antimouse antibody was then added and the sample again incubated at $37^{\circ} \mathrm{C}$ for one hour. After a final washing $100 \mu$ l of ABTS substrate was added and after two hours of incubation at room temperature in the dark the plates were read at 495 nm on an ELISA plate reader. The concentration of fibronectin was determined by reference of the absorbance for each well to a series of absorbance values obtained from known concentrations of fibronectin. Each sample was assayed in triplicate and the mean values determined. The lower limit of this assay was $1.0 \mu \mathrm{g} / \mathrm{ml}$ and the interassay coefficent of variation was less than $5 \%$.

\section{STATISTICAL METHODS}

Umbilical cord values for the two groups were compared using an unpaired $t$ test. Repeated measures analysis of variance was used to compare serial measurements during the study period. Significance was accepted at the $\mathrm{p}<0.05$ level. Calculations were performed using a statistical analysis software package (SAS Institute).

\section{Results}

A total of 36 infants were recruited in the six month study period. The mean (SD) gestational age for the group was $27 \cdot 1(1 \cdot 7)$ weeks. A total of 33 septic workups were performed on 24 of these infants during the first eight weeks of life. Eleven episodes of bacterial septicaemia were documented in 11 individual infants; in the other 22 episodes cultures remained negative and an alternative explanation for the initial symptoms was determined. Results from these episodes formed the control group. In 10 infants septicaemia was due to coagulase negative staphylococci, and in one Klebsiella pneumoniae. The baseline fibronectin values were obtained a median of three days (range 1-8) before the episode of suspected infection. The workup for suspected sepsis were performed at a median age of 12 days (range 6-36 days). The figure shows the results for the two groups. There were no differences in umbilical cord fibronectin concentrations between those infants who went on to develop

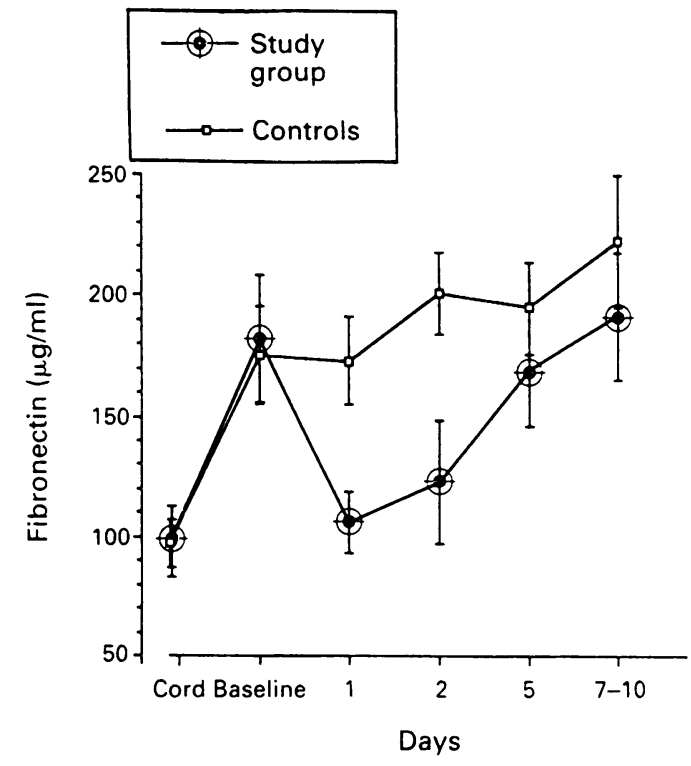

Plasma fibronectin concentrations in neonates with (study group) or without septicaemia. Cord or baseline (before an episode of sepsis) fibronectin concentrations are not significantly different between the two groups. Fibronectin concentrations decrease significantly in the neonates with septicaemia coincident with the septic episode, returning to the control group levels after five days.

septicaemia and those who did not (mean (SD) 98 (15) $v 97$ (10) $\mu \mathrm{g} / \mathrm{ml} ; \mathrm{p}=0.94)$. Baseline values of fibronectin gradually increased over time so that immediately before septic workup they were higher than the cord values. Baseline values (before the septic workup) were not significantly different for the two groups (mean 182 (26) $v 175$ (20) $\mu \mathrm{g} / \mathrm{ml}$; $\mathrm{p}=0.99)$.

Values for the infants with septicaemia decreased significantly with the onset of the episode of septicaemia (see figure). Mean fibronectin concentrations for the septic group were $106(13) v 173(18) \mu \mathrm{g} / \mathrm{ml}(\mathrm{p}=0.007)$ for the controls on day 1 of the episode of infection and remained significantly lower on day 2 (123 (26) $v 201$ (17) $\mu \mathrm{g} / \mathrm{ml} ; \mathrm{p}=0.015)$. Concentrations for the control group increased slightly during the study period.

By days 5 and 7-10 the concentrations for the study group had increased to 170 (24) and $192(26) \mu \mathrm{g} / \mathrm{ml}$ respectively and were not significantly different from those for the controls (195 (19) and $223(28) \mu \mathrm{g} / \mathrm{ml}$; $\mathrm{p}$ values $=0.69$ and 0.72 )

\section{Discussion}

Immunodeficiencies in the preterm newborn infants are well known and include decreased concentrations of total immunoglobulin and specific immunoglobulin subclasses, decreased chemotaxis and bactericidal activity of neutrophils, and decreased complement levels. ${ }^{4}$ The clinical observation that neonates, particularly those born preterm, are susceptible to infection confirms these observations. Attempts at immunotherapeutic intervention with intravenous immunoglobulin or granulocyte transfusions have yielded mixed results ${ }^{19-22}$ and attention has turned to fibronectin deficiency as a possible factor in neonatal sepsis with 
potential implications for treatment. Fibronectin has widespread and important roles in the immune response. ${ }^{7-15}$

Fibronectin is able to stimulate monocyte production of tumour necrosis factor, particularly if the fibronectin has been degraded to fragments. ${ }^{23}$ Activated neutrophils, for example during sepsis, induce fragmentation of fibronectin, 24 and fragmented fibronectin induces further neutrophil degranulation. ${ }^{25}$ Hence fibronectin has an important amplification role in neutrophil activation.

The multiadhesive properties of fibronectin are illustrated by its ability to not only bind micro-organisms such as staphylococcus ${ }^{13}$ and streptococcus, ${ }^{14}$ but to function as a key adhesion molecule in the endothelial extracellular matrix, as it is known to take part in an important early step of inflammation-adhesion of neutrophils to the vascular endothelium. ${ }^{26}$

Additionally, fibronectin has an important role in lymphocyte activation. Activation of $\mathrm{T}$ cells through anti-CD3 is augmented by fibronectin using the VLA-4 and VLA-5 integrins, ${ }^{27}$ as is CD4 activation. ${ }^{28} \mathrm{~B}$ Cells are also induced to adhere to fibronectin through VLA- $4,{ }^{29}$ and natural killer cells are stimulated to migrate through fibronectin coated surfaces. ${ }^{30}$ Given this myriad of immune functions of fibronectin, abnormalities in fibronectin in the neonate are likely to have significant effects on the ability of the neonate to respond to and control infective pathogens.

Previous studies have shown that fibronectin concentrations are lower in term newborn infants than in older children and adults ${ }^{16}$ and may be lower still in the preterm infant ${ }^{17}$; it has been suggested that fibronectin deficiency may decrease the ability of newborn infants to resist or clear bacterial infection. ${ }^{31}$

Our study shows no relation between plasma fibronectin concentrations at birth or in early neonatal life and subsequent development of bacterial sepsis in extremely preterm infants. Septicaemia was, however, associated with a significant and sustained decrease in fibronectin concentrations. Gerdes showed a similar decrease in fibronectin in term and preterm infants with sepsis compared with 'known' normal ranges at each gestation. ${ }^{31}$ Our study used each infant's own preceding fibronectin concentration as a baseline and showed significant decreases ( $\geqslant 25 \%$ of baseline) in fibronectin concentrations in eight of 11 infants with septicaemia compared with three of 22 $(p<0.001)$ infants without septicaemia.

The decreased concentrations associated with sepsis may be due to increased consumption of fibronectin in response to the increased clearance of products of the inflammatory response or to decreased production or release of fibronectin from the liver. Potential adverse effects of decreased concentrations during infective episodes include delayed clearance of infection due to decreased opsonisation, impaired neutrophil migration, phagocytosis and localisation to sites of infection, and a decreased rate of clearance of byproducts of bacteriolysis. In addition, fibronectin deficiency may contribute to the development of capillary leak, shock, formation of pulmonary oedema, and disseminated intravascular coagulation. Some workers have reported an improvement in immune function after fibronectin transfusion in adults with major illness or trauma ${ }^{32} 33$ and a single study has shown an improvement in opsonic activity in the plasma of preterm infants after correction of fibronectin deficiency. ${ }^{34}$

Given the important part fibronectin plays in the immune response to infection, the considerable decrease in concentration occurring during sepsis in the preterm neonate requires further evaluation. The potential exists for the use of fibronectin as an adjunctive immunotherapy in preterm infants. Such intervention strategies remain to be explored.

1 Klein JO, Marcy SM. Bacterial sepsis and meningitis. In: Remington JS, Klein JO, eds. Infectious disease of the fetus and newborn infant. Philadelphia: Saunders, 1983: and new $679-35$.

2 Jarvis WR. Epidemiology of nosocomial infections in pediatric patients. Pediatr Infect Dis $\mathcal{F}$ 1987; 6: 344-51.

3 Hemming VG, Overal JC, Britt MR. Nosocomial infections in a newborn intensive-care unit: results of forty-one months of surveillance. N Engl f Med 1976; 294: 1310-6.

4 Yoder MC, Polin RA. Immunotherapy of neonatal septicemia. Pediatr Clin North Am 1986; 33: 481-501.

5 Hynes R. Molecular biology of fibronectin. Annu Rev Cell Biol 985; 1: 67-90.

6 Mosher DF. Physiology of fibronectin. Annu Rev Med 1984; 35: 561-75.

7 Procter RA. Fibronectin: an enhancer of phagocytic function. Rev Infect Dis 1987; 9 (suppl 4): S412-7.

8 Gudewicz PW, Molnar J, Lai MZ, et al. Fibronectin-mediated uptake of gelatin-coated latex particles by peritoneal macrophages. F Cell Biol 1980; 87: 427-33.

9 Pommier CG, O'Shea J, Chused T, et al. Studies on the fibronectin receptors of human peripheral blood leucocytes: morphological and function characterisation. $\mathcal{f}$ Exp Med 1984; 159: 137-51.

10 Norris DA, Clark RAF, Swigart LM, Huff JC, Weston WL, Howell SE. Fibronectin fragments are chemotactic for human peripheral blood monocytes. F Immunol 1982; 129: human perip.

11 Hakansson L, Venge P. The combined action of hyaluronic acid and fibronectin stimulates neutrophil migration. f Immunol 1985; 135: 2735-9.

12 Beezhold DH, Lause DB. Stimulation of rat macrophage interleukin 1 secretion by plasma fibronectin. Immunol Invest 1987; 16: 437-49.

13 Procter RA. The staphylococcal fibronectin receptor: evidence for its importance in invasive infection. Rev Infect Dis 1987; 9 (suppl 4): S335-40.

14 Chatwal GS, Blobel H. Heterogenicity of fibronectin reactivity among streptococci as revealed by binding of fibronectin fragments. Comp Immun Microbiol Infect Dis 1987; 10: 99-108.

15 Hill HR, Shigeoka AO, Augustine NH, Pritchard D, Lundblad JL, Schwartz RS. Fibronectin enhances the opsonic and protective activity of monoclonal and polyclonal antibody against group B streptococci. $f$ Exp Med 1984; 159: 1618-28.

16 Cafferty $\mathrm{MH}$, Lepow $\mathrm{M}$, Saba TM, et al. Normal fibronectin levels as a function of age in the pediatric population. Pediatr Res 1983; 17: 482-5.

17 Yoder MC, Douglas SD, Gerdes J, Kline J, Polin RA Plasma fibronectin in healthy newborn infants: respiratory distress syndrome and perinatal asphyxia. $\mathcal{f}$ Pediatr 1983 ; 102: $777-80$.

18 Grossman JE. Plasma fibronectin and fibronectin therapy in sepsis and critical illness. Rev Infect Dis 1987; 9 (suppl 4): S428-30.

19 Baley JE, Stork EK, Warkentin PI, Shurin SB. Buffy coat transfusions in eutrophenic neonates with presumed sepsis: a prospective randomised trial. Pediatrics 1987; 80: 712-20.

20 Laurenti F, Ferro R, Isacchi G, et al. Polymorphonuclear leukocyte transfusion for the treatment of sepsis in the newborn infant. $\mathcal{F}$ Pediatr 1981; 98: 118-23.

21 Clapp DW, Kleigmann RM, Baley JE, et al. Use of intravenously administered immune globulin to prevent nosocomial sepsis in low birth weight infants: report of a pilot comial sepsis in low birth weight in

22 Baker CJ, Melish ME, Hall RT, et al. Intravenous immune globulin for the prevention of nosocomial infection in low globulin for the prevention of nosocomial infection in low

23 Beezhold DH, Personius C. Fibronectin fragments stimulate tumor necrosis factor secretion by human monocytes. 7 Leuk Biol 1992; 51: 59-64.

24 Brown DM, Brown GM, Macnee W, Donaldson K. Activated human peripheral blood neutrophils produce epithelial injury and fibronectin breakdown in vitro. Inflammation 1992; 16: 21-30. 
25 Wachtfogel YT, Abrams W, Kucich U, Weinbaum G, Schapira M, Colman RW. Fibronectin degradation products containing the cytoadhesive tetrapeptide stimulate human neutrophil degranulation. $\mathcal{f}$ Clin Invest 1988; 81: $1310-6$.

26 Forsyth KD, Simpson AC, Fitzpatrick MM, Barratt TM, Levinsky RJ. Neutrophil-mediated endothelial injury in haemolytic-uraemic syndrome. Lancet 1989; ii: 411-4.

27 Davis LS, Oppenheimer-Marks N, Bednarczyk JL, McIntyre BW, Lipsky PE. Fibronectin promotes proliferation of naive and memory $T$ cells by signalling liferation of naive and memory T cells by signalling through both VLA-4 and

28 Matsuyama T, Yamada A, Kay J, et al. Activation of CD4 cells by fibronectin and anti CD 3 antibody. A synergistic effect mediated by the VLA-5 fibronectin receptor complex. F Exp Med 1989; 170: 1133-48.

29 Garcia-Pardo A, Wayner EA, Carter WG, Ferreira OC Jr. Human B lymphocytes define an alternative mechanism of adhesion to fibronectin: the interaction of the alpha 4 beta 1 integrin with the LHGPEILDVPST sequence of the type III connecting segment is sufficient to promote cell attachment. F Immunol 1990; 144: 3361-6.

30 Somersalo K, Saksela E. Fibronectin facilitates the migration of human natural killer cells. Eur f Immunol 1991; 21: $35-42$.

31 Gerdes JS, Yoder MC, Douglas SD, Polin RA. Decreased plasma fibronectin in neonatal sepsis. Pediatrics 1983; 72: 877-81.

32 Saba TM, Blumenstock FA, Shah DM, et al. Reversal of fibronectin and opsonic deficiency in patients. Ann Surg

33 Scovill WA, Saba TM, Blumenstock FA, Bernard $H$, Powers SR Jr. Opsonic $\gamma-2$ surface binding glycoprotein therapy during sepsis. Ann Surg 1978; 188: 521-9.

34 Hill HR, Shigeoka AO, Augustine NH, Pritchard D, Lundblad JL, Schwartz RS. Fibronectin enhances the opsonic and protective activity of monoclonal and polyclonal antibody against group B streptococci. 7 Exp Med 1984; 159: 1618-28.

$\frac{1}{3}$ 무 